\title{
Optimasi Fuzzy Inference System pada Sistem Deteksi Fibrilasi Atrium dengan Fitur Elektrokardiogram
}

\author{
Kemas Farosi, ${ }^{*}$ Nuryani, ${ }^{\dagger}$ dan Darmanto \\ Jurusan Fisika, Fakultas Matematika dan Ilmu Pengetahuan Alam, \\ Universitas Sebelas Maret, Jln. Ir. Sutami 36A Kentingan Surakarta 57126
}

\begin{abstract}
Intisari
Penelitian tentang deteksi fibrilasi atrium (FA) menggunakan elektrokardiogram dan Fuzzy Inference System (FIS) telah dilaksanakan. Fitur yang digunakan adalah statistik interval RR yaitu rata-rata interval $R R\left(R_{a v e}\right)$ dan standar deviasi interval $R R\left(R_{s t d}\right)$. Optimalisasi arsitektur FIS yang dilakukan berupa variasi pada jumlah fitur interval RR, fungsi keanggotaan FIS dan metode defuzzifikasi FIS. Berdasarkan hasil eksperimen, arsitektur FIS terbaik dalam mendeteksi FA adalah yang menggunakan kedua fitur $\left(\mathrm{RR}_{a v e}\right.$ dan $\left.\mathrm{RR}_{s t d}\right)$ sekaligus dengan fungsi keanggotaan gaussian dan metode defuzzifikasi mean of maxima. Kinerja pada arsitektur tersebut dinyatakan dengan sensitivitas, spesitifitas dan akurasi yang masing-masing secara berurutan bernilai $81,55 \%, 82,12 \%$ dan $81,93 \%$.
\end{abstract}

\section{ABSTRACT}

\begin{abstract}
A study on the detection of atrial fibrillation using electrocardiogram and fuzzy inference system (FIS) has been succesfully conducted. Statistical features of RR interval namely mean and standard deviation of RR interval is used. FIS architecture is optimized by variation number of features, FIS membership function and defuzzification methods. Based on experimental result, the best FIS architecture in FA detection is both statistical features $\left(\mathrm{RR}_{a v e}\right.$ and $\left.\mathrm{RR}_{s t d}\right)$ at once, with gaussian membership functions and mean of maxima deffuzification method. The best architecture performances are $81,55 \%, 82,12 \%$ and $81,93 \%$ in terms of sensitivity, specificity and accuracy, respectively.
\end{abstract}

KATA KUNCI: Atrial fibrillation,RR interval,fuzzy inference system http://dx.doi.org/10.12962/j24604682.v13i1.2130

\section{PENDAHULUAN}

Jantung adalah salah satu organ penting bagi manusia yang fungsi utamanya untuk memompa darah yang kaya oksigen keseluruh tubuh [1]. Berdasarkan hal tersebut maka gangguan terhadap jantung dapat berakibat fatal bagi manusia. Salah satu gangguan yang dapat menggangu kinerja jantung adalah Fibrilasi Atrium (FA).

FA disebabkan karena kerusakan fungsi mekanik pada atrium jantung yang menyebabkan tidak beraturnya aktivitas atrium jantung [2]. Kondisi tersebut menyebabkan darah yang diterima oleh atrium tidak terdistribusi secara efektif menuju ventrikel. Darah tersebut mengalir secara pasif dari atrium menuju ventrikel menyebabkan efisiensi ventrikel menurun sekitar 20\% hingga 30\% dari kondisi normal [3].

FA ini merupakan salah satu gangguan jantung yang sering ditemui dan penyumbang signifikan dalam morbiditas dan mortalitas pada penyakit kardiovaskular [4]. Studi yang telah dilakukan oleh Miyasaka tahun 2006 [5] menunjukkan bahwa pada tahun 2000 di Amerika Serikat sendiri terdapat 5,1 juta penderita penyakit FA. Jumlah ini meningkat pada

\footnotetext{
*E-MAIL: kemasfarosi@student.uns.ac.id

${ }^{\dagger}$ E-MAIL: nuryani@mipa.uns.ac.id
}

tahun 2050 yang diestimasikan sekitar 12,1 juta hingga 15,9 juta penderita FA.

Salah satu cara dalam mendeteksi kehadiran FA dapat menggunakan alat elektrokardiogram (EKG). EKG merupakan alat yang merepresentasikan aktivitas elektrik dari otot jantung dalam bentuk grafik [6]. Alat EKG yang selama ini yang digunakan didunia medis masih memiliki beberapa kelemahan yaitu belum adanya sistem otomatisasi dalam menganalisis EKG. Analisis EKG yang dilakukan selama ini oleh tenaga medis masih bersifat manual. Berdasarkan hal tersebut maka diperlukan sistem otomatisasi dalam mendiagnosis kehadiran FA menggunakan sistem pengolahan informasi.

Salah satu sistem pengolahan informasi adalah fuzzy inference system (FIS). FIS merupakan sistem pengolahan informasi yang didasarkan pada pengambilan keputusan buatan yang dioperasikan dengan memanfaatkan prinsip penalaran manusia [7]. Menurut Passino dan Yurkovich tahun 1998 [8] arsitektur sistem kecerdasan FIS ditunjukkan pada Gambar 1.

Penelitian ini memanfaatkan fitur statistik RR dari gelombang EKG yang digunakan sebagai masukkan FIS. Menurut Tatento \& Glass (2011) [9] fitur RR ini dapat menjadi dasar dalam membedakan antara FA atau normal. Fitur statistik yang digunakan adalah rata-rata interval $\mathrm{RR}\left(\mathrm{RR}_{\text {ave }}\right)$ dan standar deviasi interval $\mathrm{RR}\left(\mathrm{RR}_{s t d}\right)$. Optimalisasi terhadap arsitektur FIS dilakukan agar didapatkan arsitektur paling baik dalam mendeteksi FA. 


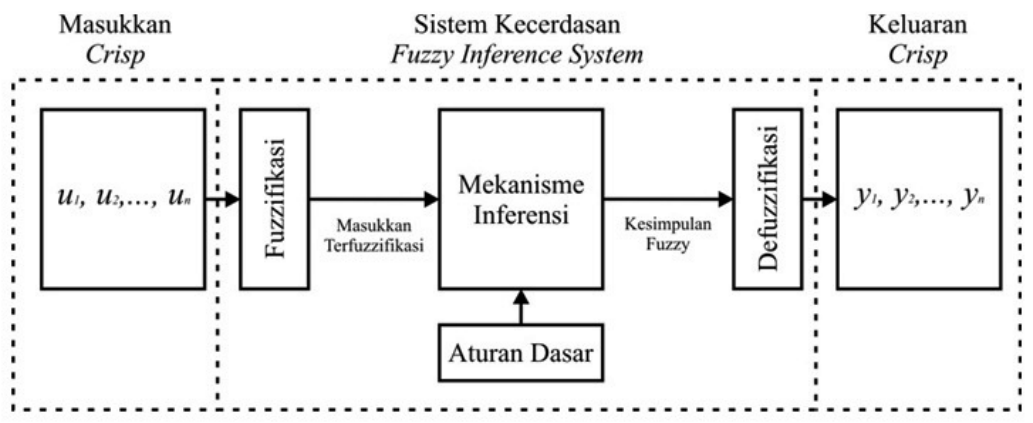

Gambar 1: Arsitektur sistem FIS.

\section{METODE PENELITIAN}

Data EKG yang digunakan adalah data sekunder yang diambil dari basis data aritmia MIT-BIH. Jumlah data EKG sebanyak 17 pasien yaitu pasien dengan frekuensi pengambilan sampel sebesar $360 \mathrm{~Hz}$. Data tersebut kemudian diolah menggunakan perangkat lunak processing 3,0 dan MATLAB. Perangkat lunak processing 3,0 difungsikan untuk ekstraksi fitur statistik RR, sedangkan MATLAB digunakan untuk proses klasifikasi oleh FIS.

Penentuan kinerja terhadap sistem FIS terdiri dari dua tahap yaitu tahap pelatihan dan tahap pengujian. Tahap pelatihan ditujukan untuk optimalisasi arsitektur FIS dalam mendeteksi FA. Optimalisasi ini dilakukan pada parameter lebar dan titik tengah fungsi keanggotaan dengan nilai linguistik pertama pada setiap variasi fuzzifikasi dan defuzzifikasi. Data yang digunakan pada tahap ini sebesar $10 \%$ dari total keseluruhan data. Sedangkan pada tahap pengujian dilakukan de-ngan menggunakan $90 \%$ sisa data keseluruhan hasil dari ekstraksi fitur statistik.

Pada penelitian ini dilakukan beberapa variasi dengan menggunakan kedua fitur statistik $\mathrm{RR}_{a v e}$ dan $\mathrm{RR}_{\text {std }}$ sebagai masukan FIS. Variasi pada proses fuzzifikasi ditujukan untuk menentukan fungsi keanggotaan yang paling optimal antara fungsi keanggotaan segitiga atau gaussian. Sedangkan pada proses defuzzifikasi ditujukkan untuk menentukan metode defuzzifikasi yang optimal antara centroid atau mean of maxima.

\section{HASIL DAN PEMBAHASAN}

Hasil ekstraksi fitur menunjukkan bahwa untuk kondisi FA memiliki 11.517 segmen sedangkan untuk kondisi normal sebanyak 19.336 segmen. Setiap segmen tersebut terdiri dari 5.000 titik data EKG.

Pendekatan dalam meninjau distribusi statistika hasil ekstraksi fitur $\mathrm{RR}_{\text {ave }}$ dan $\mathrm{RR}_{\text {std }}$ dapat menggunakan box plot. Penggunaan box plot ini ditujukan untuk membandingkan sekumpulan data yang saling berkaitan. Bagian atas dan bagian bawah pada persegi panjang ditentukan menggunakan nilai quartil atas dan quartil bawah dari sekumpulan data. Sedangkan garis horizontal yang memotong persegi panjang mencerminkan median dari data [10].

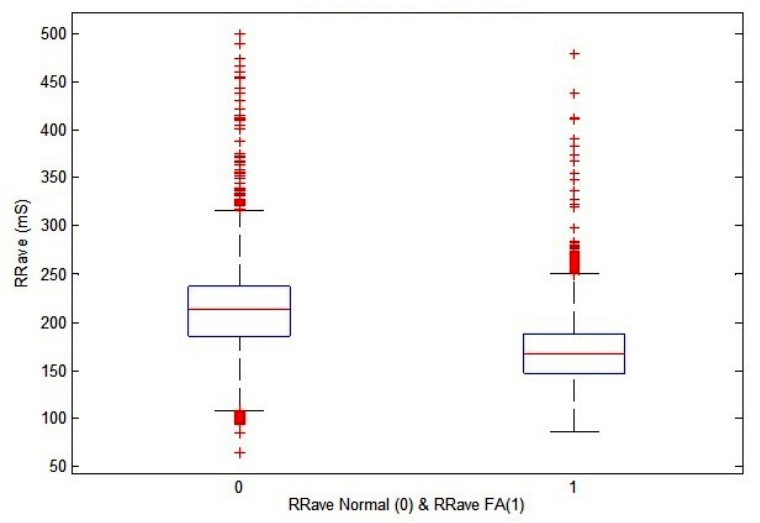

Gambar 2: Grafik box plot fitur $\mathrm{RR}_{a v e}$ untuk normal (0) dan FA (1).

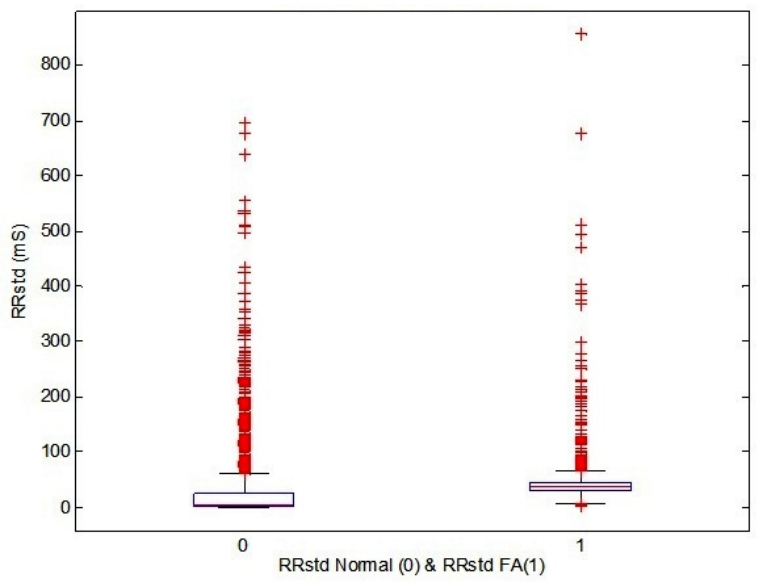

Gambar 3: Grafik box plot fitur $\mathrm{RR}_{\text {std }}$ untuk normal (0) dan FA (1).

Berdasarkan Gambar 2 terdapat perbedaan distribusi kedua data dimana $\mathrm{RR}_{\text {ave }}$ untuk FA memiliki posisi lebih rendah jika dibandingkan dengan $\mathrm{RR}_{a v e}$ untuk normal. Perbedaan tersebut dijadikan dasar untuk mendeteksi kehadiran FA, dimana $\mathrm{RR}_{\text {ave }}$ untuk FA memiliki nilai median sebesar 167,22 dan lebih kecil jika dibandingkan $\mathrm{RR}_{a v e}$ untuk normal sebesar 213,61. Hal ini disebabkan karena tidak beraturnya aktivitas atrium jantung sehingga ritme jantung meningkat [2].

Berdasarkan Gambar 3 terdapat perbedaan posisi box an- 
TABEL I: Aturan dasar arsitektur FIS pada sistem seluruh variasi.

\begin{tabular}{|c|c|}
\hline P r e m i s & Konsekuens \\
\hline$\widetilde{R R}_{\text {ave }{ }_{1}^{1}}^{\text {input }} \widetilde{R R}_{s t d_{1}^{1}}^{\text {input }}$ & $\widetilde{R R}_{k o n_{1}^{1}}^{\text {input }}$ \\
\hline$\widetilde{R R}_{\text {ave } e_{1}^{1}}^{\text {input }} \widetilde{R R}_{\text {std } d_{1}^{2}}^{\text {input }}$ & $\widetilde{R R}_{\text {kon } 1}^{\text {input }}$ \\
\hline$\widetilde{R R}_{\text {ave } 1}^{\text {input }} \widetilde{R R}_{\text {std }}^{\text {input }}$ & $\widetilde{R R}_{\text {kon }}^{\text {in }}{ }_{1}^{\text {input }}$ \\
\hline$\widetilde{R R}_{\text {ave } e_{1}^{2}}^{\text {input }} \widetilde{R R}_{\text {std } d_{1}^{1}}^{\text {input }}$ & $\widetilde{R R}_{\text {kon } 1}^{\text {input }}$ \\
\hline$\widetilde{R R}_{\text {ave }{ }_{1}^{2}}^{\text {input }} \widetilde{R R}_{\text {std }_{1}^{2}}^{\text {input }}$ & $\widetilde{R R}_{\text {kon }_{1}^{2}}^{\text {input }}$ \\
\hline$\widetilde{R R}_{\text {ave } e_{1}^{2}}^{\text {input }} \widetilde{R R}_{\text {std } d_{1}^{3}}^{\text {input }}$ & $\widetilde{R R}_{\text {kon }{ }_{1}^{2}}^{\text {input }}$ \\
\hline$\widetilde{R R}_{\text {ave } e_{1}^{3}}^{\text {input }} \widetilde{R R}_{\text {std }_{1}^{1}}^{\text {input }}$ & $\widetilde{R R}_{\text {kon }{ }_{1}^{2}}^{\text {input }}$ \\
\hline$\widetilde{R R}_{\text {ave }{ }_{1}^{3}}^{\text {input }} \widetilde{R R}_{\text {std } d_{1}^{2}}^{\text {input }}$ & $\widetilde{R R}_{\text {kon }_{1}^{3}}^{\text {input }}$ \\
\hline$\widetilde{R R}_{\text {ave } e_{1}^{3}}^{\text {input }} \widetilde{R R}_{\text {std } d_{1}^{3}}^{\text {input }}$ & $\widetilde{R R}_{\text {kon }_{1}^{3}}^{\text {input }}$ \\
\hline
\end{tabular}

tar kedua distribusi data dengan data normal memiliki posisi yang lebih rendah jika dibandingkan dengan FA. Posisi ini mengindikasikan bahwa pada kondisi normal, fitur $\mathrm{RR}_{\text {std }}$ memiliki konsistensi yang baik jika dibandingkan dengan fitur $\mathrm{RR}_{\text {std }}$ pada kondisi FA. Hal ini ditunjukkan oleh median pada fitur $\mathrm{RR}_{\text {std }}$ untuk FA sebesar 36,44 sedangkan untuk normal sebesar 4,94. Perbedaan nilai tersebut dikarenakan pada kondisi FA ritme jantung yang ditandai oleh fitur $\mathrm{RR}_{\text {ave }}$ tidak beraturan sehingga mempengaruhi besarnya nilai fitur $\mathrm{RR}_{s t d}$.

Hasil ekstraksi fitur kemudian menjadi masukkan ke dalam sistem FIS. Arsitektur pada sistem FIS ini dilakukan optimalisasi agar didapatkan hasil kinerja yang optimal dalam mendeteksi FA. Optimalisasi berupa variasi pada proses fuzzifikasi dengan membandingkan fungsi keanggotaan segitiga dan gaussian. Sedangkan pada proses defuzzifikasi optimalisasi dilakukan dengan membandingkan antara metode centroid dan mean of maxima.

Pembentukkan aturan dasar yang digunakan merupakan penalaran penulis terhadap sistem dengan mengutamakan konsistensi dalam pembentukkan aturan. Penalaran aturan tersebut kemudian diubah menjadi variabel lingustik yang mencerminkan sistem. Variabel linguistik inputsistem ditunjukkan pada Pers.(1) dan Pers.(3).

$$
\widetilde{R R}_{\text {ave } 1}^{\text {input }}=\left\{\begin{array}{l}
R R_{\text {ave }}^{\text {input }}=\text { Rendah }, \\
\widetilde{R R}_{\text {ave }}^{\text {input }}=\text { Sedang }, \\
\widetilde{R R}_{\text {input }}^{\text {inpe }}=\text { Tinggi },
\end{array}\right.
$$

TABEL II: Kinerja pelatihan seluruh variasi arsitektur FIS dengan fitur statistik $\mathrm{RR}_{\text {ave }}$ dan $\mathrm{RR}_{\text {std }}$.

\begin{tabular}{ccccc}
\hline \hline $\begin{array}{c}\text { Fuzzi- } \\
\text { fikasi }\end{array}$ & $\begin{array}{c}\text { Defuzzi- } \\
\text { fikasi }\end{array}$ & $\begin{array}{c}\text { Sensitivitas } \\
(\%)\end{array}$ & $\begin{array}{c}\text { Spesifitas } \\
(\%)\end{array}$ & $\begin{array}{c}\text { Akurasi } \\
(\%)\end{array}$ \\
\hline Segitiga & Centroid & 63,97 & 65,60 & 65,08 \\
Gaussian & Centroid & 78,15 & 82,97 & 81,43 \\
Gaussian & MOM & 81,55 & 82,12 & 81,93 \\
\hline \hline
\end{tabular}

$$
\widetilde{R R}_{\text {std }_{1}}^{\text {input }}=\left\{\begin{array}{l}
R R_{\text {std }}^{\text {input }}=\text { Rendah } \\
\widetilde{R R}_{\text {input }}^{\text {input }}=\text { Sedang } \\
\widetilde{R R}_{\text {std } d_{1}^{3}}^{\text {input }}=\text { Tinggi }
\end{array}\right.
$$

Variabel linguistik output sistem ditunjukkan pada Pers.(1) dan Pers.(3). Variabel ini mencerminkan kondisi kesimpulan sistem berdasarkan aturan dasar dan input sistem. Variabel linguistik output sistem ditunjukkan pada Pers.(5).

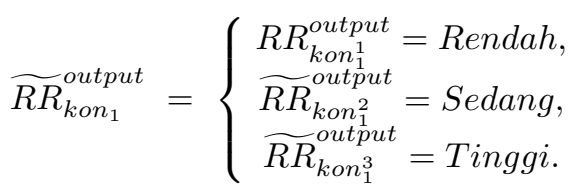

Komposisi variabel linguistik yang mecerminkan keadaan sistem kemudian diterjemahkan menjadi aturan dasar yang disusun oleh nilai lingusitik pada premis dan konsekuensi aturan dasar. Komposisi tersebut ditunjukkan pada Tabel I.

Penentuan kinerja FIS ditentukan oleh parameter spesitifitas, sensitivitas dan akurasi. Ketiga paramter ini ditunjukkan dalam bentuk prosentase. Menurut W. Zhu et al. tahun 2010 [11] perhitungan ketiga parameter tersebut ditunjukkan oleh Pers.(7) hingga Pers.(9).

$$
\begin{aligned}
\text { Spesifitas } & =\frac{T N}{T N+F P} \times 100 \%, \\
\text { Sensitivitas } & =\frac{T P}{T P+F N} \times 100 \%, \\
\text { Akurasi } & =\frac{T P+T N}{T P+T N+F P+F N} \times 100 \%,
\end{aligned}
$$

dengan TP (True Positive) adalah jumlah FA yang terdeteksi benar, FP (False Positive) adalah jumlah FA yang terdeteksi salah, TN (True Negative) adalah jumlah normal yang terdeteksi benar dan FN (False Negative) adalah jumlah normal yang terdeteksi salah.

Hasil pengujian dari ketiga variasi ditunjukkan pada Tabel II. Tahap ini menggunakan $90 \%$ data dari jumlah keseluruhan data. Hasil tersebut menunjukkan bahwa kinerja terbaik dari seluruh variasi yang dilakukan adalah variasi yang ketiga. Pada variasi tersebut memiliki arsitektur yang menggunakan kedua fitur statistik $\mathrm{RR}_{\text {ave }}$ dan $\mathrm{RR}_{\text {std }}$ sekaligus dengan hasil fungsi keanggotaan gaussian yang ditunjukkan pada Gambar 4 dan metode defuzzifikasi MOM. 


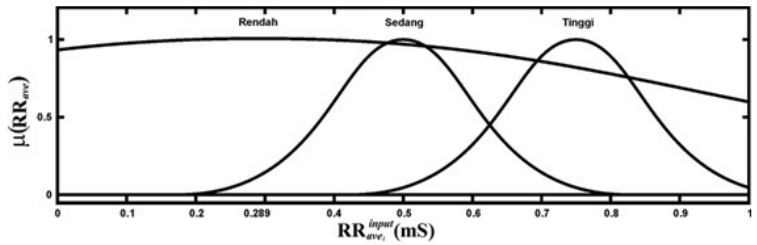

(a)

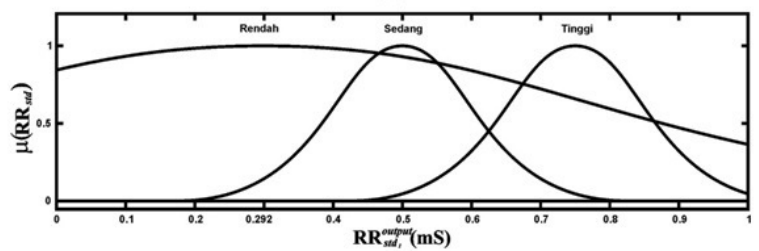

(b)

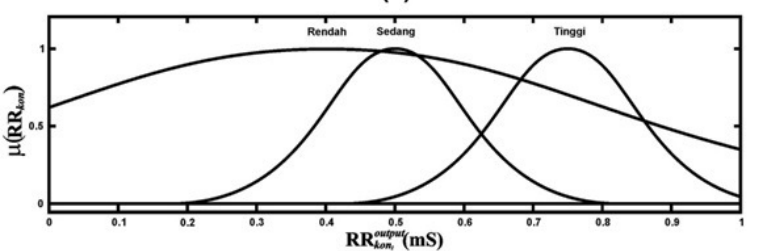

(c)

Gambar 4: Hasil fungsi keanggotaan optimal pada variabel linguistik (a). $\widetilde{R R}_{\text {ave } e_{1}}^{\text {input }}$ (b) $\widetilde{R R}_{\text {std }_{1}}^{\text {input }}$ dan (c) $\widetilde{R R}_{\text {kon }_{1}}^{\text {input }}$.

Penggunaan kecerdasan FIS dalam klasifikasi gelombang EKG telah dilakukan oleh Sahu et.al tahun 2013 [12]. Fokus penelitian tersebut adalah penggunaan kecerdasan FIS untuk mengklasifikasikan kondisi gelombang EKG apakah termasuk aritmia atau normal. Sedangkan penggunaan fitur statistik interval RRuntuk klasifikasi antara FA dan normal telah terbukti menunjukkan hasil yang baik pada penelitian Tatento dan Glass pada tahun 2011 [9]. Pada penelitian tersebut, proses klasifikasi menggunakan uji normalitas KolmogorovSmirnov dengan memanfaatkan fitur statistik interval RR. Pendekatan lain dalam mengklasifikasi FA dan normal telah dilakukan oleh Nuryani et. alpada tahun 2015 [13] menggunakan kecerdasan FIS. Penelitian tersebut memanfaatkan fiturjumlah puncak dan lebar puncak gelombang $\mathrm{P}$ pada EKG, yang kemudian fitur tersebut menjadi masukkan FIS. Pada penelitian tersebut, sistem deteksi FA yang dirancang memiliki kinerja dengan akurasi sebesar 75,09\%, lebih rendah dari sistem deteksi yang diusulkan pada penelitian ini dengan akurasi sebesar $81,93 \%$.

\section{SIMPULAN}

Pada penelitian ini telah dirancang sistem deteksi FA dengan menggunakan fitur statistik interval RR. Variasi dilakukan agar didapatkan arsitektur FIS terbaik dalam mendeteksi FA. Arsitektur tersebut adalah yang menggunakan kedua fitur statistik $\left(\mathrm{RR}_{\text {ave }}\right.$ dan $\left.\mathrm{RR}_{\text {std }}\right)$ dengan proses fuzzifikasi menggunakan fungsi keanggotaan gaussian dan metode defuzzifikasi MOM. Arsitektur ini menggunakan mekanisme inferensi Mamdani untuk menentukan inferensi sistem yang didasarkan pada aturan dasar yang dibentuk. Kinerja pada arsitektur tersebut ditunjukkan oleh tiga parameter yaitu sensitivitas, spesitifitas dan akurasi yang secara beturut-turut bernilai $81,55 \%, 82,12 \%$ dan $81,93 \%$.
[1] L. Sornmo, P. Laguna, Bioelectrical Signal Processing in Cardiac and Neurological Applications (1st Edition, Elsevier Academic Press, Burlington, 2005).

[2] S. Bellet, Clinical Disorders of the Heart Beat (3rd. ed, Lea \& Febiger, Philadelphia, 1971).

[3] E.J. Hall, C.A. Guyton, Textbook of medical physiology (12th edition, Elsevier, Philadelphia, 2011).

[4] Y.K. Ju, et. al., Frontiers in Physiology, 6, 86 (2015).

[5] Y. Miyasaka, et. al., Circulation Journal of American Heart Association, 114, 119-125 (2006).

[6] S.R. Mane, et. al., International Journal of Engineering Research and Applications, 3, 327-332 (2013).

[7] G. Chen, T.T. Pham, Fuzzy Sets, Fuzzy Logic, and Fuzzy Control Systems (CRC Press LLC, Florida, 2011).

[8] M.K. Passino, S. Yurkovich, Fuzzy Control (Addison Wesley
Longman, California, 1998).

[9] P. Tatento, L. Glass, Medical and Biological Engineering and Computing, 39, 664-671 (2011).

[10] Y. Benjamini, The American Statistician, 42(4), 257-262 (1988).

[11] W. Zhu, N. Zeng, N., N. Wang, Sensitivity, specificity, accuracy, associated confidence interval and ROC analysis with practical SAS implementations, NESUG proceedings: health care and life sciences, Baltimore, Maryland, 1, 1-9, 2010.

[12] Sahu, K. Nitin, S. Ayub, J.P. Saini, International Journal of Advanced Research in Computer Science and Software Engineering, 3(11), 925-932 (2013).

[13] N. Nuryani, et. al., Procedia Computer Science, 72, 154-161 (2015). 